\title{
PRODUTIVIDADE E BEM ESTAR DE VACAS LEITEIRAS EM SISTEMAS SILVIPASTORIS - REVISÃO DE LITERATURA
}

\section{Luciene Laurett ${ }^{1}$ \\ Pâmela Vieira Coelho²}

Resumo: O sistema silvipastoril constitui ou modelo de uso da terra, em que as atividades silviculturais e pecuárias são combinadas para gerar produção de forma complementar pela interação dos seus componentes: pasto, árvore e animal; diminuindo os impactos ambientais negativos, próprio dos sistemas tradicionais pecuários. O desempenho produtivo das vacas leiteiras está relacionado ao conforto térmico, sendo que, vacas leiteiras submetidas ao estresse térmico têm sua produtividade limitada, pois diminuem a ingestão de alimento nas horas mais quentes do dia. Nesse contexto, essa revisão tem como objetivo apontar diferença no bem estar proporcionado aos animais criados em sistemas convencionais e silvipastoris; a fim de elucidar a influência do sistema silvipastoril sobre o bem estar de vacas leiteiras.

Palavras-chave: Bem estar animal; Conforto térmico; Sustentabilidade.

\footnotetext{
${ }^{1}$ Graduanda em agronomia, Instituto Federal do Espírito Santo (IFES), Brasil. E-mail: lucienelaurett@gmail.com. 2 Graduanda em agronomia, Instituto Federal do Espírito Santo (IFES), Brasil. E-mail: pamelatatolinck@hotmail.com.
} 